\title{
Gender differences in public perceptions on National Health Insurance
}

\author{
M Evans, O Shisana \\ Human Sciences Research Council, Plein Street, Cape Town \\ M Evans, MA \\ O Shisana, MA, ScD \\ Corresponding author: O Shisana (oshisana@hsrc.ac.za)
}

\begin{abstract}
Background. Implementation of National Health Insurance (NHI) commenced recently. With the promise of addressing drastic inequalities in the health sector, NHI has the potential to positively transform the health system. In particular, NHI could have a significant positive impact on females, who are disadvantaged under the current system, with higher rates of poor health and lower rates of medical scheme membership compared with males. Despite NHI's transformative potential, however, the public discourse on NHI as portrayed in the media suggests that it is an unpopular policy. The evidence presented in this paper is to the contrary.

Objectives. To assess the general public's opinion on NHI and to explore gender differences in perceptions.

Methods. This paper reports on findings from a 2010 cross-sectional nationally representative survey of the South African population that assessed social attitudes, including perceptions on NHI. Sex-disaggregated data were analysed in SPSS version 20.

Results and conclusions. There is broad public acceptance of NHI, indicating that an overwhelming majority of South Africans would prefer an NHI system to the current two-tiered system. Support for NHI has increased since similar studies in 2005 and 2008, with the simultaneous growth of public discourse on the policy. More females than males support NHI, reflecting the potential of the NHI system to have a positive impact on gender equality and the health of women and girls.
\end{abstract}

S Afr Med J 2012;102(12):918-924. DOI:10.7196/SAMJ.6397

In 2007, the governing party resolved to implement National Health Insurance (NHI), setting in motion the process of developing a policy to effect this resolution. The Minister of Health then appointed a Ministerial Advisory Committee on NHI, which worked with the Department of Health, leading to the release of the Green Paper. ${ }^{1}$ The NHI pilot programmes began in 2012, marking the beginning of a 14-year implementation period for the new health system. The move towards NHI signifies a radical health policy shift from an inequitable two-tiered private/public system to a national singlepayer system that will ensure universal health coverage accessible to all citizens and legal residents - free at the point of care.

$\mathrm{NHI}$ is in line with the prevailing international consensus that universal healthcare systems reduce social disparities in health through removing financial barriers to health services. ${ }^{2-4}$ The current two-tiered system leaves the public sector underfunded, under-capacitated, and lacking in infrastructure and resources compared with the private sector, and NHI will reduce these inequities by drastically improving public healthcare. ${ }^{4,5}$ In line with the third United Nations Millennium Development Goal, to promote gender equality and empower women, NHI healthcare reform also has the potential to promote gender equality. ${ }^{6,7}$ It could greatly improve the health of women and girls by providing all South African citizens and legal residents with health coverage and by strengthening public facilities used by the majority of all females residing in the country.

This paper provides insight on gender differences in public perceptions on NHI. Popular support is critical for effective implementation of NHI. Following the publication of the Green Paper, some have argued that NHI is not a positive step for the country's development. ${ }^{8}$ The critics argue against the fundamental constitutional principle of the right to healthcare. In this paper we provide empirical evidence that this resistance does not in fact reflect citizens' opinions on NHI.
Public perceptions on NHI have been measured previously; $;, 10$ however, gender differences in perceptions of NHI have not yet been explored. There are gender differences in health-seeking behaviour, ${ }^{11}$ and these may affect perceptions of NHI. We hypothesise that, since females have much to gain from the implementation of NHI, their rates of support will be higher than those of males. To examine public perceptions on NHI and gender differences, this paper analyses data from a national public opinion survey to answer the following questions: (i) to what extent does the public support NHI? and (ii) are there gender differences in the degree of support?

\section{Methods}

The data used are from the Human Sciences Research Council (HSRC)'s 2010 South African Social Attitudes Survey (SASAS), an annual cross-sectional population survey that assesses contemporary public opinions. SASAS yields a nationally representative sample of adults aged 16 and older, using the HSRC's Master Sample framework that consists of 1000 primary sampling units. ${ }^{12}$ The study used a questionnaire to measure perceptions on NHI. In August - October 2010, data were collected through face-to-face interviews with one randomly selected respondent per visiting point. The NHI module was administered to 3112 respondents; the response rate was $89 \%$. When the sample data were weighted and compared with the mid-year population estimates in terms of sex, age and race, a less than $3 \%$ difference was found, suggesting that the sample is indeed nationally representative $e^{13}$ despite its exclusion of institutionalised and homeless people. Ethical clearance was received from the HSRC Ethics Committee.

The 2010 data reflect public opinion on NHI before publication of the Green Paper in 2011. The forthcoming 2012 South African National Health and Nutrition Survey will track opinions following its release. Data on NHI perceptions were sex-disaggregated and stratified by demographic characteristics (race, marital status, 
education level, employment status and location of residence), self-assessed health status and type of healthcare used (private, public, etc.), and are presented in Table 1. The cut-off point for strong support of NHI was set at $60 \%$. Differences $\geq 5 \%$ between comparable groups were considered worthy of comment. Using SPSS version 20, chi-square tests were conducted to test for differences between groups. A $p$-value of $<0.05$ was considered statistically significant.

\section{Results}

Overall, support for NHI was very high (Table 2); 90.8\% of respondents believed that NHI should be a national priority, and over

Table 1. Demographic characteristics of the SASAS 2010 sample by sex $(\%)$

\begin{tabular}{|c|c|c|c|}
\hline & $\begin{array}{c}\text { All } \\
(N=3 \text { 112) }\end{array}$ & $\begin{array}{c}\text { Males } \\
(n=1268)\end{array}$ & $\begin{array}{c}\text { Females } \\
(n=1844)\end{array}$ \\
\hline \multicolumn{4}{|l|}{ Sex } \\
\hline Male & 47.8 & & \\
\hline Female & 52.2 & & \\
\hline \multicolumn{4}{|l|}{ Race } \\
\hline Black African & 76.6 & 76.1 & 77.1 \\
\hline Coloured & 9.3 & 8.5 & 10.1 \\
\hline Indian or Asian & 2.9 & 3.5 & 2.5 \\
\hline White & 11.1 & 11.9 & 10.3 \\
\hline \multicolumn{4}{|l|}{ Marital status } \\
\hline Spouse & 44.7 & 46.3 & 43.2 \\
\hline No spouse & 55.3 & 53.7 & 56.8 \\
\hline \multicolumn{4}{|l|}{ Education } \\
\hline No education & 3.4 & 1.8 & 4.8 \\
\hline Some primary/secondary & 53.9 & 50.1 & 57.5 \\
\hline Secondary & 31.8 & 35.3 & 28.6 \\
\hline Tertiary & 10.9 & 12.8 & 9.1 \\
\hline \multicolumn{4}{|l|}{ Employment status } \\
\hline Full-time & 28.8 & 36.2 & 22.0 \\
\hline Un/under-employed & 44.5 & 35.7 & 52.7 \\
\hline Pension/sick/disabled/other & 13.6 & 13.0 & 14.1 \\
\hline Student & 13.1 & 15.1 & 11.2 \\
\hline \multicolumn{4}{|l|}{ Location of residence } \\
\hline Urban formal & 54.7 & 56.7 & 52.9 \\
\hline Urban informal & 10.9 & 10.4 & 11.3 \\
\hline Tribal & 28.9 & 26.3 & 31.2 \\
\hline Rural formal & 5.5 & 6.5 & 4.7 \\
\hline \multicolumn{4}{|l|}{ Health status } \\
\hline Very poor/poor & 16.9 & 14.9 & 18.7 \\
\hline Average & 26.9 & 26.9 & 26.9 \\
\hline Good/excellent & 56.2 & 58.2 & 54.4 \\
\hline \multicolumn{4}{|l|}{ Type of health care } \\
\hline Medical scheme member & 24.9 & 28.1 & 22.1 \\
\hline Pay out of pocket/go without & 19.0 & 21.0 & 17.2 \\
\hline Public/mostly public system & 56.0 & 50.9 & 60.7 \\
\hline
\end{tabular}

$80 \%$ would prefer it to the current healthcare system. Most thought that it was better to provide NHI than to hold down taxes, that NHI would be good for their families, and that NHI would improve the quality of healthcare. Nearly $70 \%$ of respondents would use NHI if services were free.

Support for NHI was stronger among females than males (Table 2): a higher proportion of females than males preferred NHI to holding down taxes $(76.1 \%$ v. $70.0 \%)$, and thought that their families would be better off with NHI (76.1\% v. 68.5\%) and that NHI would improve healthcare quality $(76.1 \%$ v. $70.8 \%)$.

Gender differences in the level of support for NHI between racial categories were statistically significant for black African, coloured and white females. All three racial categories supported NHI at higher rates than their male counterparts (Table 2). Black African and coloured females supported NHI the most, and white males supported it the least. Females supported NHI regardless of their marital status (Table 2). Single females appeared to be stronger supporters of NHI than single males, and indicated that they thought introduction of NHI was preferable to holding down taxes (79.1\% v. 69.1\%).

Both males and females were supporters of NHI but the strength of support depended on level of education. In general, females supported NHI in higher rates than males regardless of educational status (Table 3), although gender differences were only statistically significant for some primary or secondary education and for tertiary education. Females with some primary or secondary education were the highest supporters of NHI among males and females according to education level. Interestingly, females with tertiary education supported NHI over holding down taxes at a higher rate than their male counterparts. Females with tertiary education compared to their male counterparts also indicated that they would utilise NHI services (70.4\% v. $46.1 \%)$.

There was more support for NHI among females compared with males across all employment categories (Table 4). Females who were students, unemployed or underemployed, and pensioned or disabled were the strongest supporters of NHI. Similar to respondents with tertiary education, male students supported holding down taxes over $\mathrm{NHI}$ at higher rates than female students (20.4\% v. 6.9\%).

Females generally supported NHI at higher rates than males across all locations of residence (Table 4), although gender differences were only statistically significant for those living in formal urban or rural tribal authority areas. Females living in rural tribal authority areas compared to their male counterparts were the strongest supporters of NHI: they believed that NHI would improve the quality of public healthcare at a higher rate than did their male counterparts $(87.3 \%$ v. $77 \%)$.

Regardless of health status, there was more support for NHI among females than males (Table 5). Gender differences were statistically significant for those in poor and in good health. Females in poor health supported NHI the most, particularly thinking it more important than holding down taxes compared with males ( $78.8 \% \mathrm{v}$. $67.7 \%)$. A higher proportion of females than males in good health also thought that their families would be better off with NHI $(75.7 \%$ v. 65.4\%). There was stronger support for NHI among females than males regardless of type of healthcare facility (Table 5), gender differences being statistically significant among medical scheme members and public health facility users. Importantly, females who used the public system supported NHI the most, indicating that they would prefer NHI to holding down taxes at a higher rate than males (81.9\% v. $72.8 \%)$. Even females with medical scheme membership thought that their families would be better off with $\mathrm{NHI}$ at a higher rate than their male counterparts $(67.4 \%$ v. $52.3 \%)$. 


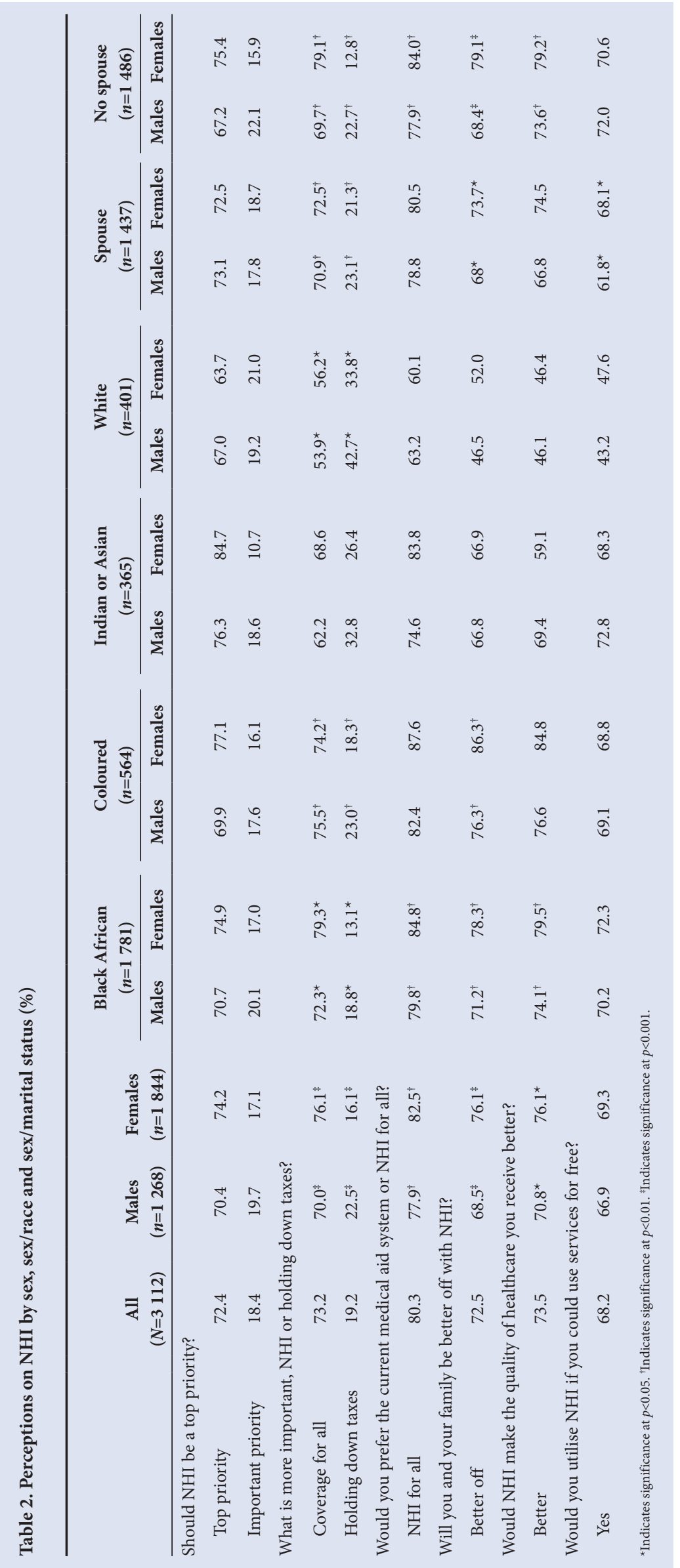

\section{Discussion}

Public support is critical for the effective implementation of NHI over the next 14 years. Support for NHI has grown from $56.9 \%$ in $2005^{9}$ to $73.2 \%$ in $2008 .{ }^{10}$ The present study indicates that support for NHI has increased again, now standing at $90.8 \%$. This overwhelming support is not surprising, given the challenges presented by the public health system on the one hand and the high cost of private healthcare on the other, as was observed by McIntyre et al., who found that the majority of South Africans were dissatisfied with the current healthcare system and thought private health care was expensive. ${ }^{10}$ Even medical scheme members are not fully protected from health costs; according to McIntyre et al., ${ }^{4}$ they accounted for over $60 \%$ of out-of-pocket healthcare payments. This may explain why people belonging to medical schemes supported NHI in $2008^{10}$ as well as in the current study. Okorafor suggests that the NHI tax may have little impact on the demand for private health insurance; $;^{14}$ however, our study conversely suggests that over half of medical scheme members would indeed utilise NHI.

Racial differences continue to define perceptions of socio-economic policies in South Africa. Although the majority of whites supported NHI, $42.7 \%$ of white males and $33.8 \%$ of white females would prefer the government to hold down taxes rather than make healthcare accessible to all. Historical and current inequalities from the legacy of apartheid could explain these differences. Whites had and still have access to education, employment and private medical insurance at higher rates than other race groups; they therefore contribute proportionately more to taxes. ${ }^{15}$ Nevertheless, their contribution should be judged against the fact that all South Africans contribute to VAT, which comprises $27 \%$ of tax revenue. ${ }^{16}$

Support for NHI was strong among both males and females; however, the data support our hypothesis that females are stronger supporters of NHI than males. This support is independent of race, marital status, education, employment, location of residence, health status and type of healthcare used.

The stronger support for NHI among single females compared with single males could be because single females are more likely to earn lower incomes and to be single parents than their male counterparts. Partnered females' stronger support of NHI compared with partnered males could be explained by females' gendered role as family caregivers. Education seems to play an important role in support for NHI, as more respondents with little education (especially females) than those with higher education supported NHI. Lower support of NHI among respondents with higher education could be because they are more likely to have higher incomes and to pay higher taxes than those with less education. Most interestingly, 
Table 3. Perceptions on NHI by sex/education level (\%)

\begin{tabular}{|c|c|c|c|c|c|c|c|c|}
\hline & \multicolumn{2}{|c|}{$\begin{array}{l}\text { No education } \\
\quad(n=122)\end{array}$} & \multicolumn{2}{|c|}{$\begin{array}{l}\text { Some primary/secondary } \\
\qquad(n=1636)\end{array}$} & \multicolumn{2}{|c|}{$\begin{array}{l}\text { Secondary diploma } \\
(n=911)\end{array}$} & \multicolumn{2}{|c|}{$\begin{array}{l}\text { Tertiary diploma/ degree } \\
(n=377)\end{array}$} \\
\hline & Males & Females & Males & Females & Males & Females & Males & Females \\
\hline \multicolumn{9}{|c|}{ Should NHI be a top priority? } \\
\hline Top priority & 59.8 & 71.6 & 71.3 & 76.1 & 71.0 & 70.6 & 64.7 & 74.6 \\
\hline Important priority & 27.0 & 11.7 & 17.3 & 16.9 & 21.0 & 19.2 & 25.8 & 14.5 \\
\hline \multicolumn{9}{|c|}{ What is more important, NHI or holding down taxes? } \\
\hline Coverage for all & 73.2 & 73.9 & 72.7 & 81.1 & 70.6 & 69.8 & $57.5^{\ddagger}$ & $66.6^{\ddagger}$ \\
\hline Holding down taxes & 9.4 & 4.4 & 19.1 & 12.7 & 21.7 & 21.7 & $38.9^{\ddagger}$ & $25.1^{\ddagger}$ \\
\hline \multicolumn{9}{|c|}{ Would you prefer the current medical aid system or NHI for all? } \\
\hline NHI for all & 92.9 & 80.1 & 80.3 & 85.3 & 76.5 & 79.6 & 71.8 & 74.8 \\
\hline \multicolumn{9}{|c|}{ Will you and your family be better off with NHI? } \\
\hline Better off & 89.1 & 71.6 & $70.6^{\dagger}$ & $81.0^{\dagger}$ & 70.3 & 71.0 & 50.9 & 63.9 \\
\hline \multicolumn{9}{|c|}{ Would NHI make the quality of healthcare you receive better? } \\
\hline Better & 89.1 & 60.5 & $73.7^{\star}$ & $82.7^{\star}$ & 71.8 & 68.4 & 52.5 & 69.8 \\
\hline \multicolumn{9}{|c|}{ Would you utilise NHI if you could use services for free? } \\
\hline Yes & 43.6 & 63.6 & 72.4 & 71.0 & 67.7 & 66.4 & $46.1^{*}$ & $70.4^{*}$ \\
\hline
\end{tabular}

the proportion of male students ( 1 in 5) who would prefer to hold down taxes rather than provide coverage to all was more than double the rate of female students having that opinion. Students' likelihood of having privileged socio-economic backgrounds could discourage their support for NHI; however, females with higher education are likely to earn less than males, and the socialisation of females as caregivers could encourage female students' empathy for others and result in increased support for NHI.

As expected, support for NHI was found to be stronger among the unemployed than the employed, possibly because unemployed people are less likely to be members of medical aid schemes. Females living in rural tribal authority areas face barriers to healthcare access such as affordability and accessibility ${ }^{10}$ that could explain their being the greatest supporters of $\mathrm{NHI}$ according to location of residence.

Medical scheme membership is largely determined by socioeconomic status, and the majority of medical scheme members (89\%) belonged to the two richest household quintiles. ${ }^{4}$ This could explain the observation that a higher proportion of males than females were members of medical schemes. ${ }^{10}$ Similar to findings from $2008,{ }^{10}$ we found increased support for NHI among public health users (particularly females) and less support among medical scheme members, which could suggest that public healthcare users recognise the benefits of NHI to the public health system. Finally, those in poor health supported NHI more than those in good health. Individuals in poor health are likely to be more frequent users of the health system and therefore may be more inclined to recognise the benefits NHI has to offer. The much higher proportion of females in poor health who supported NHI over holding down taxes compared with males in poor health could be explained by their being more likely than their male counterparts to seek medical attention. ${ }^{11}$ However, despite medical scheme membership and health status, females were stronger supporters of NHI than males.
Females' stronger support for NHI could be influenced by a combination of factors: their lower socio-economic status (employment, income and education), lower medical scheme membership, and poorer health status compared with males. However, other unmeasured factors must be taken into consideration. Females' gendered role as caregivers could encourage them to perceive NHI as a benefit not only for themselves, but also for their families and communities. Females have a particular interest in the health of their families, as they are the ones who care for children and the elderly two groups that often have health problems. Furthermore, females' sexual and reproductive health needs as well as their poor health status could encourage them to seek healthcare more frequently than men; they are therefore important users of health systems.

What do these gender differences in NHI support mean? To answer this question, it is necessary to consider the context within which females express their views on NHI. Females in this country carry a huge burden of disease, mainly HIV, tuberculosis and other chronic diseases. ${ }^{7,17}$ Additionally, they face high maternal mortality rates and gender-based violence. ${ }^{18,19}$ Females face specific challenges in the health system related to inequitable access to health services (particularly for those living in rural areas), gendered stigma from healthcare providers, disregard for sexual and reproductive rights, and dependence on the public health system because low income and un/ under-employment bar membership to private medical schemes., ${ }^{7,18}$ Furthermore, in their gendered roles of mothers and caregivers, females disproportionately suffer the repercussions of an inequitable health system. ${ }^{7,17}$ They care for children who suffer from preventable conditions requiring frequent healthcare visits. They are the major users of the public health system, which is inadequately staffed, overcrowded, and experiences frequent shortages of medicines. ${ }^{7,17}$

A well-funded health system would be able to increase health personnel in each facility and reduce overcrowding, thereby 


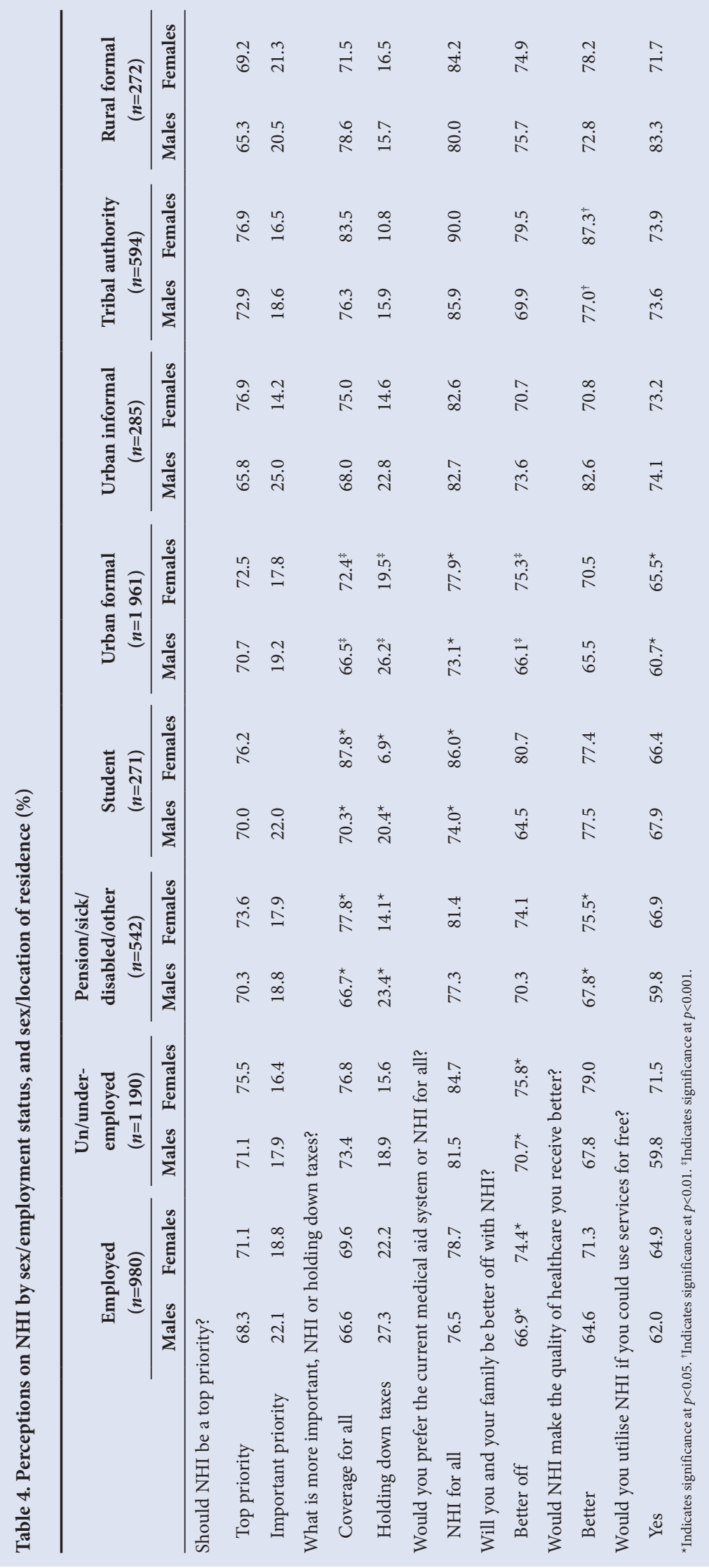

augmenting the attention healthcare providers are able to pay to patients. A well-funded health system may also reduce or even end shortages of medicines.

Since females bear the brunt of a nonfunctional healthcare system, they are looking for relief. Research has shown that with regard to healthcare it was most important to South Africans that primary healthcare workers were adequately trained and could carry out patient referrals, that medicine was available, and that staff-patient interactions were empathetic. ${ }^{20}$ Furthermore, researchers found that nonmedical scheme members incurred a higher burden of medical payments in comparison with medical scheme members, that poor households paid a disproportionate share of out-of-pocket payments, and that some of those eligible for fee exemptions were still required to pay at the point of care. ${ }^{10}$ To females, having NHI means that they will not have to worry whether they can get an ambulance to take them to the nearest facility to obtain timely care, or whether they will be asked to pay at the point of care. Indeed, there are other barriers in addition to socio-economic factors that females face in accessing healthcare and that should be kept in mind while moving forward with NHI implementation (e.g. transportation, education, caregiving responsibilities, stigma of going to a clinic, stigma and poor treatment from health providers, or belonging to specific vulnerable groups such as women who have sex with women, gender non-conforming individuals, and sex workers). Ultimately, it remains evident that $\mathrm{NHI}$ has great potential to improve the status of females' health.

Support for publicly funded healthcare systems is high in other countries. Public support for Medicare in Canada is over $85 \%$, and the health system is considered fundamental to the country. ${ }^{21}$ Similarly, most Australians support Medicare over holding down taxes. ${ }^{22}$ Support is also high in other middle-income countries where publicly funded systems were introduced more recently. Public support for NHI in Taiwan is consistently close to $70 \%,{ }^{23}$ and in Thailand public support was found to be over $89 \% .{ }^{24}$ These examples are promising for South Africa, as they suggest that public support for NHI will continue well beyond the initial stages. Finally, the health systems of Canada, Australia, and Thailand are among the top $25 \%$ in the world according to the World Health Organization (WHO) global rankings of health systems, a measure that considers both quality and cost of care, ${ }^{25}$ confirming again that NHI has the potential to bring about positive change to healthcare in South Africa.

\section{Conclusion}

We set out to answer two questions: (i) to what extent does the public support NHI? and (ii) are 


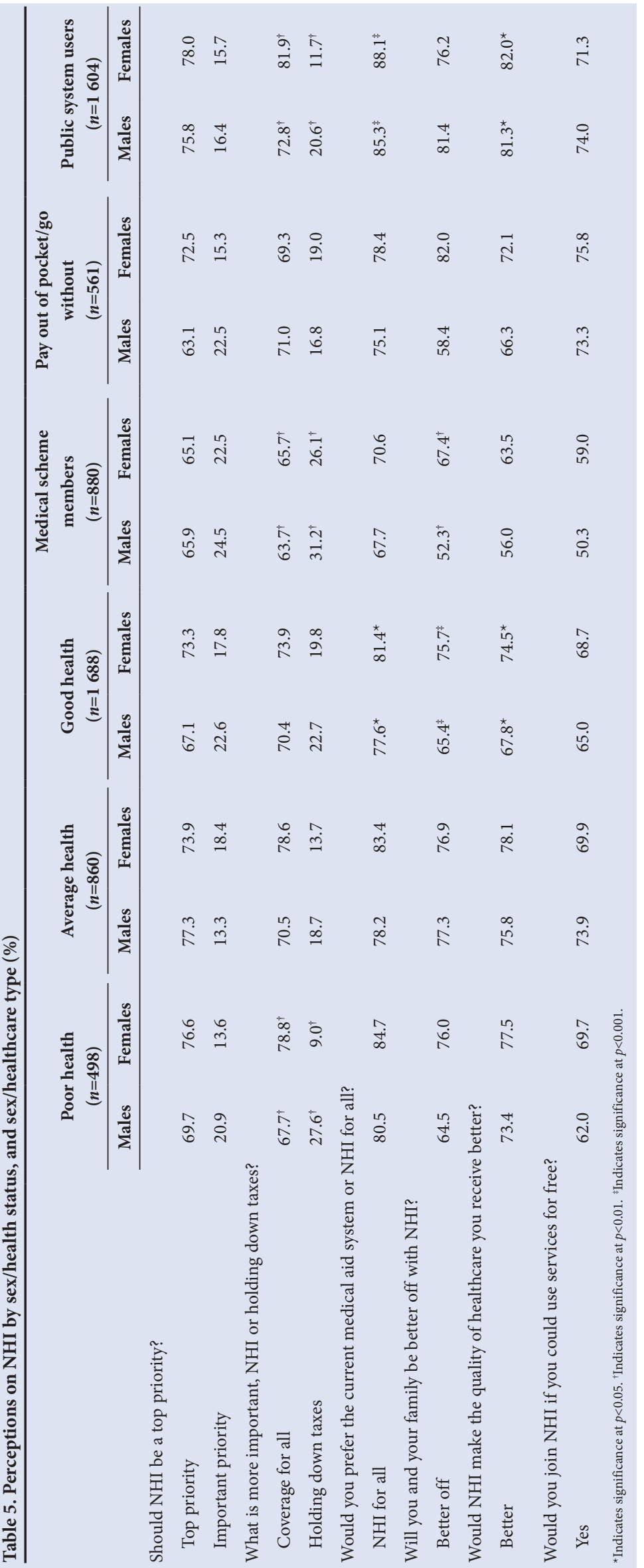

there gender differences in the degree of support for NHI? On the basis of the study results, we conclude that South Africans overwhelmingly support NHI and that females support it to a greater extent than males. Most interestingly, the majority of the population would prefer to support NHI rather than to hold down taxes, suggesting that the government can move NHI forward with confidence that the majority of the population supports the policy. Nevertheless, it remains worthwhile to consider the minority's views and evaluate their impact on the design of NHI.

The right to healthcare access is guaranteed by the South African Constitution and is a goal of the $\mathrm{NHI}$ policy. $\mathrm{NHI}$ has the potential to reduce gender inequality in healthcare through significantly reducing the disproportionate monetary barriers to healthcare that females face, and this potential is reflected by females' stronger support of NHI. The WHO highlights that the consideration of gender is important to the development of health policy, ${ }^{26}$ and Amollo has previously argued that females should be actively involved in the design and planning of NHI. ${ }^{7}$ Because of NHI's impact on the health of females (and because they are more likely to use the services at first implementation), we concur that it is important that their voices are heard in public discourse and community consultations, and that gender considerations are included as South Africa moves forward with this critically important improvement to its health system.

References

Department of Health. National Health Insurance Policy Paper. Pretorin Department of Health, 2011.

2. World Health Organization. The World Health Report 2010 - Health Systems Financing. Geneva: World Health Organization, 2010. http://www. who.int/whr/2010/whr10_en.pdf (accessed 23 August 2012).

3. World Health Organization. Closing the Gap in a Generation - Health Equity through Action on the Social Determinants of Health. Geneva World Health Organization, 2008. http://whqlibdoc.who.int/hq/2008/ WHO_IER_CSDH_08.1_eng.pdf (accessed 20 August 2012).

4. McIntyre D. National Health Insurance: Providing a vocabulary for public engagement. In: Padarath A, Fonn S, eds. South African Health Review. Durban: Health Systems Trust, 2010:145-156.

5. Shisana $\mathrm{O}$. Is the NHI The right solution for South Africa's inequitable health care system? In: Jansen JD, Nyamnjoh FD, Pillay U and Hagg $G$. 2013. State of the Nation 2012-3: Tackling Inequality and Poverty. Cape Town: HSRC Press, Forthcoming 2013.

6. United Nations. Millennium Development Goals (MDGs). United Nations Department of Public Information, 2010. http://www.un.org/ millenniumgoals/ (accessed 28 August 2012).

millenniumgoals/ (accessed 28 August 2012). health in South Africa? Agenda 2012;26(2):111-125. [http://dx.doi.org/10.1 health in South Africa? Agen

8. McCauley R. NHI critics mustn't lose sight of big picture. The Star 2011; 28 November. http://www.iol.co.za/the-star/nhi-critics-mustn-t-lose-sight-of big-picture-1.1187301 (accessed 10 September 2012).

9. Shisana O, Rehle T, Louw J, Zungu-Dirwayi N, Dana P, Rispel L. Public perceptions on national health insurance: Moving toward universal health coverage in South Africa. S Afr Med J 2006;96(9):814-818.

10. McIntyre D, Okorafor O, Ataguba J, et al. Health care access and utilisation, the burden of out-of-pocket payments and perceptions of the health system: Findings of a national houschold survey. Cape Town: Health Economics Fnit University of

11. Galdas PM, Cheater F, Marshall P. Men and health help-seeking behavior: literature review. J Adv Nurs 2005;49(6):616-623. [http://dx.doi. org/10.1111/j.1365-2648.2004.03331.x]

12. Roberts B, wa Kivilu M, Davids YD, eds. South African Social Attitudes Roberts B, wa Kivilu M, Davids YD, eds. South African Social Attitudes
Second Report: Reflections on the Age of Hope. Cape Town: HSRC Press, 2010

13. Statistics South Africa. Mid-Year Population Estimates 2010. Pretoria Statistics South Africa, 2010. http://www.statssa.gov.za/publications/P0302/ P03022010.pdf (accessed 29 August 2012).

4. Okorafor OA. National Health Insurance reform in South Africa: Estimating the implications for demand for private health insurance. Appl Health Eco Health Policy 2012;10(3):189-200. [http://dx.doi.org/10.2165/11594830000000000-00000] 


\section{RESEARCH}

15. Lieberman ES. Race and Regionalism in the Politics of Taxation in Brazil and South Africa. Cambridge: Cambridge University Press, 2003. [http://dx.doi.org/10.1017/CBO9780511615658]

16. National Treasury and South African Revenue Services. 2011 Tax Statistics. Pretoria: South African Revenue Services, 2011

17. Mbali M, Mthembu S. The politics of women's health in South Africa. Agenda 2012;26(2):4-14. [http:// dx.doi.org/10.1080/10130950.2012.714674]

18. Chopra M, Lawn JE, Sanders D, et al. Achieving the health Millennium Development Goals for South Africa: challenges and priorities. Lancet 2009;374(9694):1023-1031. [http://dx.doi.org/10.1016/S01406736(09)61122-3

19. Coovadia H, Jewkes R, Barron P, Sanders D, McIntyre D. The health and health system of South Africa historical roots of current public health challenges. Lancet 2009;374(9692):817-813. [http://dx.do org/10.1016/S0140-6736(09)60951-X]

20. McIntyre D, Goudge J, Harris B, Nxumalo N, Nkosi M. Prerequisites for National Health Insurance in South Africa: Results of a national household survey. S Afr Med J 2009;99(10):725-729.

21. Soroka SN. Canadian Perceptions of the Health Care System. Toronto: Health Council of Canada, 2007. http://www.queensu.ca/cora/_files/PublicPerceptions.pdf (accessed 12 September 2012).
22. Breusch T, Wilson S. After the tax revolt: Why Medicare matters more to middle Australia than lower taxes. Australian Journal of Social Issues 2004;39(2):99-116.

23. Cheng TM. Taiwan's new National Health Insurance program: Genesis and experience so far. Health Aff 2003;22(3):61-76. [http://dx.doi.org/10.1377/hlthaff.22.3.61]

24. Bumrungskulswat O. Voice of the people in the Thai National Health Security (Insurance) System. National Health Security Office, 2012. http://www.pmaconference.mahidol.ac.th/index. php?option=com_docman\&task=doc_download \&gid $=565$ (accessed 28 September 2012).

25. World Health Organization. The World Health Report 2000 - Health Systems: Improving Performance. Geneva: World Health Organization, 2000. http://www.who.int/whr/2000/en/whr00_en.pdf (accessed 28 September 2012).

26. World Health Organization. Integrating Gender Perspectives in the Work of WHO - WHO Gender Policy. Geneva: World Health Organization, 2002. http://www.who.int/gender/documents/engpolicy. pdf (accessed 28 September 2012).

Accepted 11 October 2011. 